\title{
The impact of the North Atlantic Oscillation on European hydro-power generation
}

\author{
Matteo De Felice ${ }^{1,2}$, Laurent Dubus $^{3}$, Emma Suckling ${ }^{4}$, Alberto Troccoli ${ }^{5,6}$
}

\begin{abstract}
In this paper we analyse and quantify the impact of North Atlantic Oscillation (NAO) on the daily hydropower generation in the European countries. We create a consistent dataset of hydropower generation using a machinelearning methodology, this activity is an output of the Copernicus Climate Change Service ECEM contract. The model is set up using generation data on 2015-2016, and then an artificial dataset was built over the period 19792017 , as if the installed capacity, that of 2017, had been the same all along the period, using reanalysis data for the meteorological variables. This synthetic dataset thus generated has been used to analyse the changes in national hydro-power generation (both for run-of-river and reservoir-based plants) between years when NAO is positive and when it is negative, over Europe. The results show how the majority of countries in southern Europe experience a reduction in generation during NAO positive phases. In particular the Iberian peninsula shows a clear sensitivity with change of both the hydro-power generation typologies in the range $-8 \%--4 \%$ in terms of capacity factor. This work also shows the benefit of having a pan-European dataset of energy variables spanning multiple decades to analyse the impact of climate phenomena on the European energy sector.
\end{abstract}

Keywords: Renewable Energy, Hydro-power, Reanalysis, Random Forests

Email address: matteo.de-felice@europa.eu (Matteo De Felice)

${ }^{1}$ (since March 2018) Joint Research Centre, European Commission, Petten, The Netherlands

${ }^{2}$ ENEA, Climate Impacts and Modelling laboratory, Roma, Italy

${ }^{3}$ EDF R\&D, Chatou, France

${ }^{4}$ University of Reading, Dept. of Meteorology, Reading, UK

${ }^{5}$ World Energy \& Meteorology Council c/o University of East Anglia, Norwich, UK

${ }^{6}$ University of East Anglia, School of Environmental Sciences, Norwich, UK 


\section{Introduction}

Hydro-power is a vastly used resource in Europe. During the last decade, the installed capacity was very stable because the majority of the potential has already been built, in particular for large-scale plants. Over the last ten years, the electricity produced by hydro-power (considering reservoir storage and run-of-river) in Europe was about 350 TWh per year, with five countries (Austria, France, Italy, Spain and Sweden) contributing for $70 \%$ of the total amount [1]. The importance of hydro-power for the management of national power grids is increasing due to its capability to provide flexibility to the system, an advantage in countries where there is a large fraction of variable and non-dispatchable sources like wind and solar power [2, 3]. Hydropower is also very useful to respond to peak demand, especially in winter, thanks to its fast response time. On the other hand, hydropower generation can vary significantly from one year to another, due to both water resource availability, and energy management decisions, as shown for instance for France by [3]. Hydropower resource characterization is then extremely important, and it starts from understanding the effect of climate variability on its availability.

Hydrology of water basins is affected by global climate and large-scale modes of variability in the atmosphere and oceans, particularly through major drivers like the El Niño Southern Oscillation (ENSO), which has an evident influence on the global production of hydropower as discussed by $\mathrm{Ng}$ et al. [4]. Focusing on Europe, the most important driver of climate variability is probably the North Atlantic Oscillation (NAO) [5, 6], which is known to have an impact on regional weather variations [7], particularly in winter. A review about the impact of NAO on the European streamflow can be found in [8]. The impact of NAO has been also analysed for the transport systems [9] and for solar energy [10] and wind power [11].

This work provides an analysis of the observed connection between NAO and country-averaged hydro-power production. We have used the country data provided by the ENTSO-E Transparency Platform for all the ENTSO-E Member States given the lack of data about energy generation at plant level for all the European. Working at the country-level could mask important variations within the largest countries but the objective of this work is to carry out a pan-European analysis. In fact, working at continental scale

is of critical importance to better understand the strong inter-connections 
amongst national power grids. However, different ongoing initiatives in the context of the Copernicus Climate Change Service are working to create even more detailed and accurate data sets in the near future.

The work presented here describes the methodology to generate a synthetic data set of hydro-power generation for the European countries then used to assess the impact of the NAO, described in Section 1.1. A brief literature review about the impact of the NAO on hydro-power is given in Section 1.2. Section 2 describes the meteorological and energy data used in this study. Section 3 reports the methodology applied to produce the hydro-power generation dataset and analyses its accuracy.

Section 4 describes how the NAO can be linked to run-of-river and reservoirbased hydro-power generation for a set of European countries.

We close in Section 5 by discussing the results.

\subsection{The North Atlantic Oscillation}

The North Atlantic Oscillation (NAO) is one of the major modes of climate variability of the Northern Hemisphere atmosphere [12]. It is particularly important in winter, when it exerts a strong control on the climate of the Northern Hemisphere [13]. The NAO index can be computed with two methodologies: 1) using the difference between the normalised sea level pressure over Gibraltar and the normalised sea level pressure over Southwest Iceland [14]; 2) applying a Principal Component Analysis technique to the anomalies of sea-level pressure or $500 \mathrm{mb}$ height over the Atlantic sector [12]. The index used in this paper is the daily time-series provided by the US Climate Prediction Center (CPC) calculated applying a Rotated Principal Component Analysis technique on $500 \mathrm{mb}$ height anomalies over the Northern Hemisphere ${ }^{7}$ on the NCEP/NCAR reanalysis.

The North Atlantic Oscillation (NAO) is a source of monthly frequency variability often attributed to stratosphere-troposphere coupling [15] and is known to influence winter temperatures and rainfall over Northern Europe and Central Asia [16, 17].

In 1 we show the time-series of the NAO index used in this paper highlighting the winter seasons and its phase: positive when greater than 0.5 and negative when lower than -0.5. It is worth noting that during some of the

\footnotetext{
${ }^{7}$ The procedure is described here: http://www.cpc.ncep.noaa.gov/products/ precip/CWlink/daily_ao_index/history/method.shtml
} 


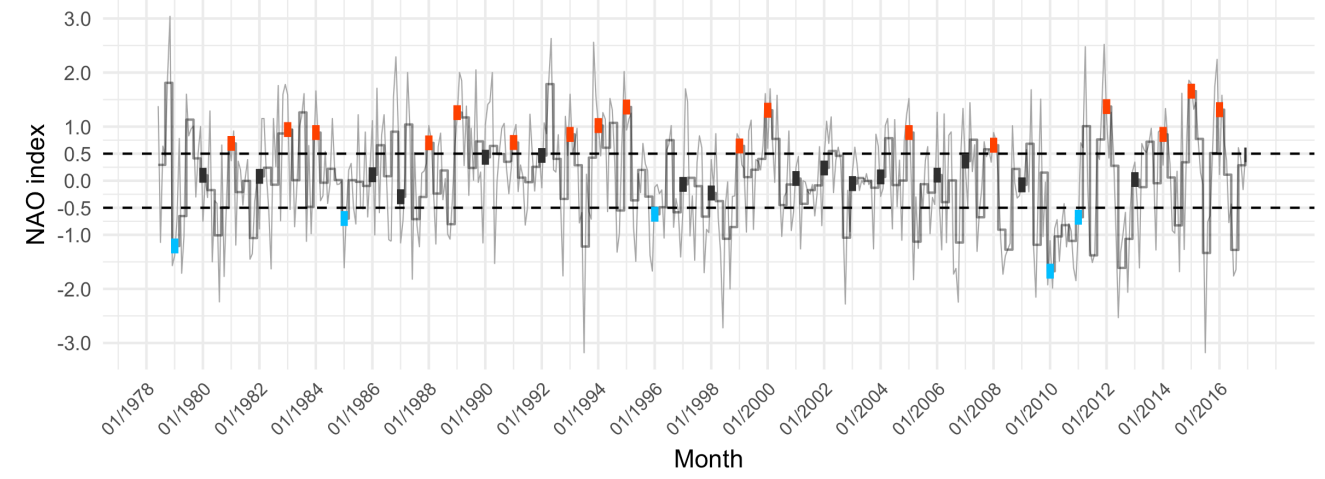

Figure 1: North Atlantic Oscillation monthly time-series for the period 1979-2016. The step line represents the seasonal averages with the coloured square highlighting the winter season. The colour defines if the NAO is in its high phase (red, 17 events), average (grey, 16 events) and low (blue, 5 events) according to a threshold of $+/-0.5$

winters with a positive or negative NAO, in Europe have been observed extreme weather events like for example the extremely cold winter of 2009/2010 $[18,19,20]$ or the winter $2015 / 2016$ which led to floods and record-breaking rainfalls in the North Hemisphere [21, 22]

\subsection{Literature review}

Engstrom and Uvo [23] describe the positive correlation between NAO and monthly hydropower production in northern Sweden and Norway during winter. They have considered 17 hydropower plants in 5 rivers taking into account NAO and other related teleconnections. Significant correlations have been found also for the most important PCA modes of river discharge and temperature in order to better evaluate the cause-effect relationships. Also Uvo and Berndtsson [24] focused their analysis on the influence of NAO on Scandinavian hydropower, analysing precipitation from 102 weather stations. The authors have shown that the influence of NAO is strongest over the Norwegian coast and southern Finland, with correlation values within 0.60.8. Another study on the Scandinavian area is proposed by [25] where a statistical model of the impacts of NAO on hydropower generation is built and used to assess its impact on the energy market.

The work by Francois [26] presents a study on the relation in the winter season between NAO and the most common renewable energy sources, namely solar, wind and run-of-river hydro power. For the latter, the authors have found that the explained variance of penetration rate (the percentage 
of energy load supplied by renewable energies) by the NAO during winter is above $30 \%$ for England, Germany and Belarus. It is worth noting that taking into account also the Scandinavian Pattern teleconnection, the explained variance increases in average by $8 \%$.

Trigo et al. [27] analyse the inter-annual variability of precipitations and riverflow in the Iberian peninsula related to the NAO phases. They show how the river flow of three large rivers in the period January-March is clearly modulated by the winter NAO and also assess its impact on hydro-electric production. Jerez et al. [28] evaluate the impact of NAO on renewable sources in the Iberian peninsula, underlining that this teleconnection is the most important driver of climate variability in this region. Their findings are that negative NAO phases increase the precipitation and thus the river streamflows, with an increase in potential hydro power generation. The authors also analyse six important reservoirs comparing the differences between the two NAO phases, evidencing significant differences in all the cases.

\section{Data}

This work combines two kinds of data, hydro-power generation and weather/climate data, in order to: 1) Create an artificial generation dataset spanning almost 40 years based on 2017 installed capacity and historical meteorological data;

2) Use the created data to analyse the impact of large-scale circulation on hydro-power generation.

A statistically robust analysis of interannual signals should be based on a dataset of observed generation data extending a few decades or longer. Furthermore, the creation of a long re-constructed dataset of hydro-power generation allows us to analyse the nexus between meteorology and hydropower, isolating the impacts of climate from the evolving energy mix.

\subsection{Generation data}

In this work we have used the generation data published on the ENTSOE Transparency Platform ${ }^{8}$ (ENTSO-E TP hereafter), which makes available all the power grids data for all the European countries since January 2015 according to the rules imposed by the EU regulation $543 / 2013^{9}$. The platform has been created to provide high-quality and timely available data to the

\footnotetext{
${ }^{8}$ https://transparency.entsoe.eu

${ }^{9}$ urlhttp://eur-lex.europa.eu/LexUriServ/LexUriServ.do?uri=OJ:L:2013:163:0001:0012:EN:PDF
} 


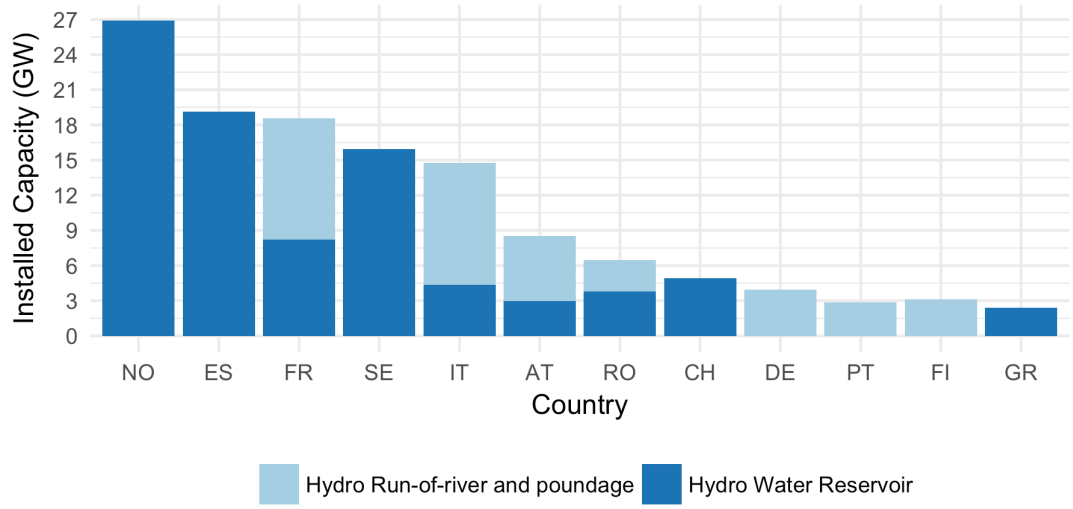

Figure 2: Hydro-power installed capacity for the twelve European countries with the highest amount of capacity. Data from Dataset 14.1.A of the ENTSO-E Transparency Platform for 2017.

energy markets' participants. The platform provides supply/demand data for all the European countries in a homogeneous way and easy to access. A review about the ENTSO-E TP, the methodology used to create the datasets and issues and limitation can be found in [29].

The type of generation data that the TSOs calculate and provide on the $\mathrm{TP}$ is described in the EU Regulation 543/2013 (for example in the Articles 14 and 16). This means that some differences can appear when comparing aggregated data from the TP with similar data obtained from other data sources. In particular, the installed capacity data we use in this work is obtained from the dataset 14.1.A (Installed Generation Capacity aggregated) and it consists of the sum of installed capacity for all the units with at least $1 \mathrm{MW}$ of capacity in a specific area.

Figure 2 summarises the widespread use of hydro-power in Europe showing the installed capacity of run-of-river and pure storage published for 2017. It is worth noting that for many countries the hydro-power generation plays a critical role in the energy supply mix, for example in Norway where hydropower generation is about the $98 \%$ of the entire national production.

Table 1 provides a summary of the values of installed capacity for the countries selected in this study.

The generation data we use in this work consists of hourly generation of national run-of-river and reservoir (Aggregated Generation per Type dataset) from 1-1-2015 to 31-10-2017. Hourly data has been then cumulated daily 


\begin{tabular}{|ll|l|l|}
\hline Country & Abbr. & Run-of-river, 2017 (MW) & Reservoir generation, 2017 (MW) \\
\hline Austria & AT & $5,580.80$ & $2,964.90$ \\
Finland & FI & 3,107 & - \\
France & FR & $10,326.98$ & $8,230.66$ \\
Germany & DE & $3,928.80$ & 1,080 \\
Greece & GR & 299 & 2,403 \\
Italy & IT & 10,389 & 4,375 \\
Norway & NO & $1,351.80$ & $26,909.50$ \\
Portugal & PT & $2,844.1$ & $1,515.30$ \\
Romania & RO & 2,681 & 3,800 \\
Spain & ES & $1,156.30$ & $19,113.30$ \\
Sweden & SE & - & 15,945 \\
Switzerland & CH & 740 & $4,897.80$ \\
\hline
\end{tabular}

Table 1: Summary of the countries selected for this study and the installed capacities used provided by the ENTSO-E Transparency Platform (data accessed in March 2018)

and transformed into capacity factor, i.e. for each day we compute the ratio between the actual production and the potential maximum (defined as the installed capacity).

Figures 3 and 4 show respectively the daily generation data of run-of-river and reservoir hydro-power from the ENTSO-E TP for the nine countries with the largest installed capacity. Generation data tend to show a high day-today variability, for this reason in the figures a 30-day rolling mean has been applied to make more evident the annual variability of generation.

\subsection{Climate data}

The analysis proposed in this work is based on multiple meteorological variables that can be related to the hydro-power generation. To have a reliable, consistent and homogenous source of meteorological information, we opted for the atmospheric reanalysis provided by ECMWF ERA-INTERIM. It provides data for several variables at global scale with a spatial resolution of about $80 \mathrm{~km}$ starting from 1979 . Here we used data for the period from 01-01-1979 to 31-10-2017 and all the variables used have been aggregated at daily resolution (most of them have a 3-hour resolution originally). Moreover, weather variables have been averaged at country level to be consistent with the generation data.

We have selected three meteorological variables: total precipitation, snow depth and 2-meter temperature. This set of variables contains all the basic information about the variability of water resources to be used for hydropower 


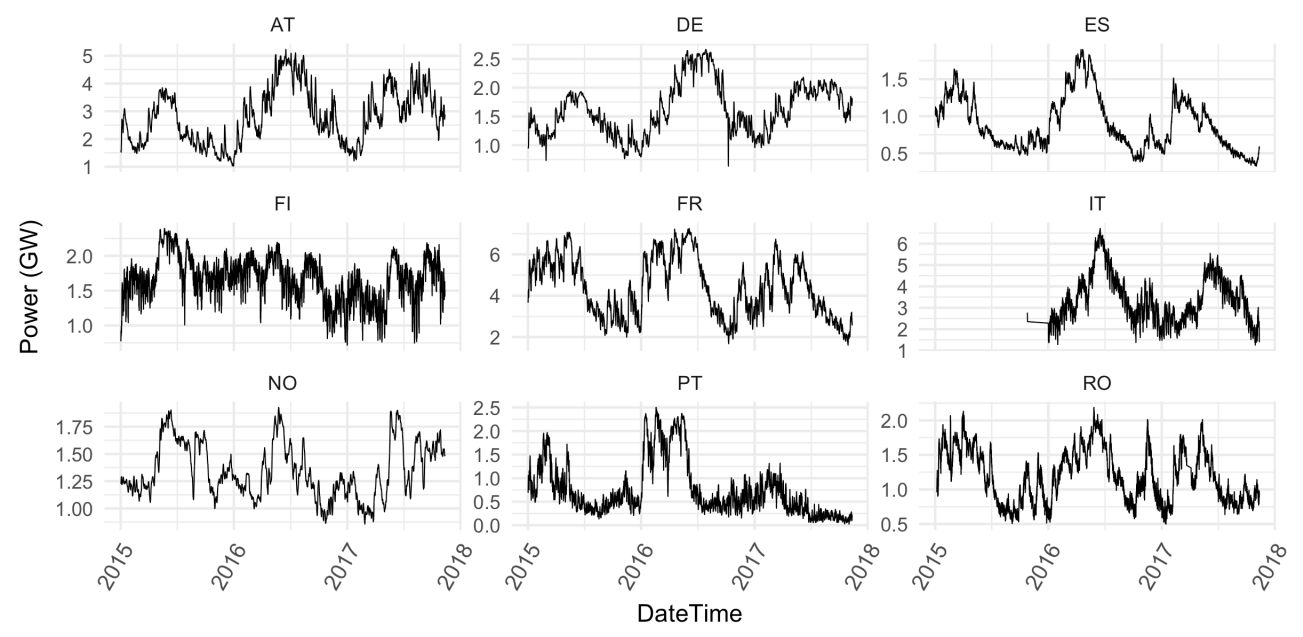

Figure 3: A visual overview of the hydro-power run-of-river generation (GW) time-series available on the ENTSO-E TP and used in this work. A 30-day rolling average has been applied to filter the high frequency variability. Some issues can be noted: Italy data for 2015 is missing, the peak of Spanish and Norwegian generation is greater than the installed capacity presented in Table 1

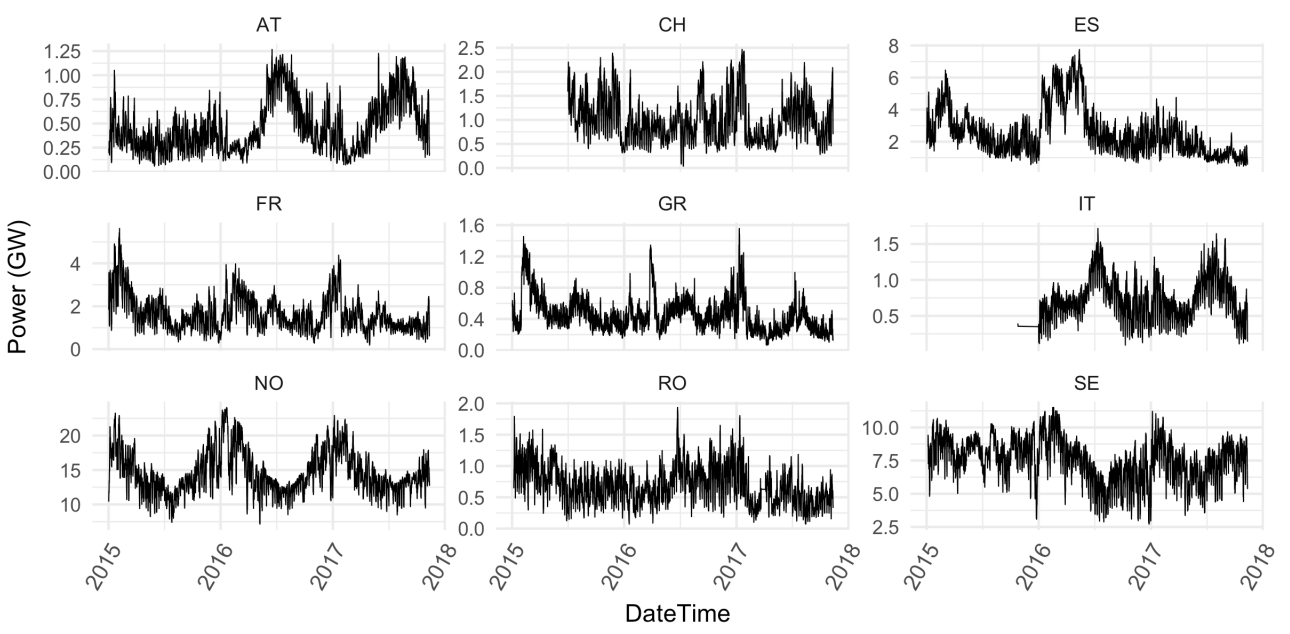

Figure 4: A visual overview of the hydro-power reservoir generation (GW) time-series available on the ENTSO-E TP and used in this work. A 30-day rolling average has been applied to filter the high frequency variability 


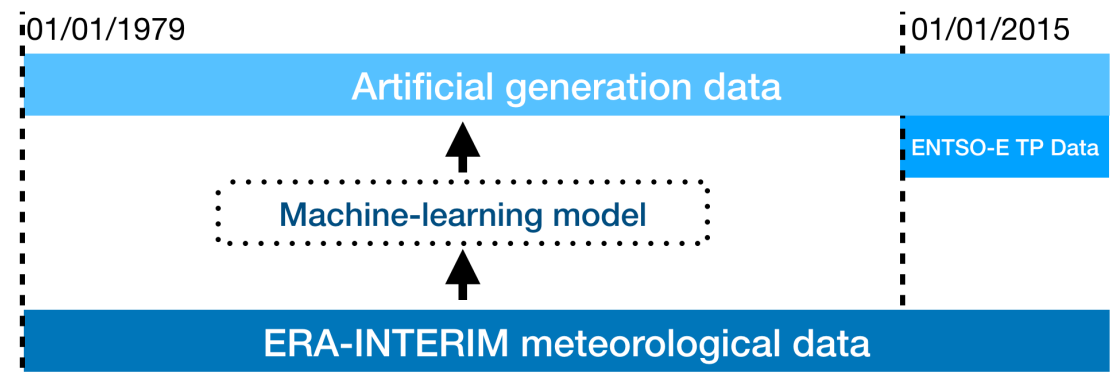

Figure 5: a diagram summarizing the data approach implemented in this paper to create a synthetic dataset. A machine-learning methodology has been applied to meteorological data and the observed data from the ENTSO-E Transparency Platform to generate an artificial data set of hydro-power generation.

generation purposes.

Despite other meteorological variables possibly having a direct link with hydro-power, for example river discharge, in this work we want to focus only on the variables commonly available also in the climate forecasts and projection. As stated in the introduction, the analysis carried out in this paper is part of a larger research activity related to ECEM, a climate service developed for the Copernicus Climate Change sectoral information systems. The ECEM service has developed as a proof-of-concept a tool able to provide information for climate and energy variables at three time-scales: historical (the object of this paper), seasonal and climate projections. In this context, this work can be seen as the first step to provide seasonal forecasts and climate projections of hydro-power generation for all the European countries.

\section{Creating a hydro-power generation dataset}

To investigate the possible influence of the NAO on the hydro-power national generation we analyse the relationship between the NAO index and hydro-power generation.

The short availability of observed generation data (less than three years) would make it impossible to carry out any robust statistical analysis between climate and production. For this reason we have implemented a methodology to extend the available data. This was done by generating synthetic production data through a machine-learning approach, as summarised in Figure 5 and described in the following section. 


\subsection{Machine-learning approach}

The approach used in this work consists of two steps:

1. A model is calibrated to learn the relationship between weather variables and daily hydro-power capacity factor observations for the years 2015-2017 (training phase)

2. The rest of the weather data (1979-2014) is used as input to the model calibrated in the previous step to generate synthetic daily capacity factor.

We opted for Random Forests (RF) model, a well-known and popular method [30] consisting of a set of decision trees built to minimise their correlation. The model has been chosen after a preliminary comparison with other models (e.g. multiple linear regression, Support Vector Regression, single regression trees) as it was the most accurate. Some results on the performance of $\mathrm{RF}$ are presented later in this section.

For each country the target variable is the daily capacity-factor and the used inputs of the RF model are the following:

- 2-metre temperature for the day $d$

- Cumulated precipitation for the last 5 days

- Cumulated precipitation for the last 30 days

- Cumulated precipitation for the last $\mathrm{N}$ days with $\mathrm{N}$ a parameter chosen by maximising the correlation with the target variable (the capacity factor for the day $d$ )

- Average of the snow depth in the last 30 days

- Average of the snow depth in the last $M$ days with $M$ a parameter chosen by maximising the correlation with the target variable (the capacity factor for the day $d$ )

The introduction of a different parameter for each target country is needed to try to "parameterise" the characteristics of the national hydro system due to the orography, the hydrology, the position of the hydro-power plants, etc. An example of the maximisation procedure is shown in Figure 6 where we can see the correlation between the French run-of-river capacity factor and the 


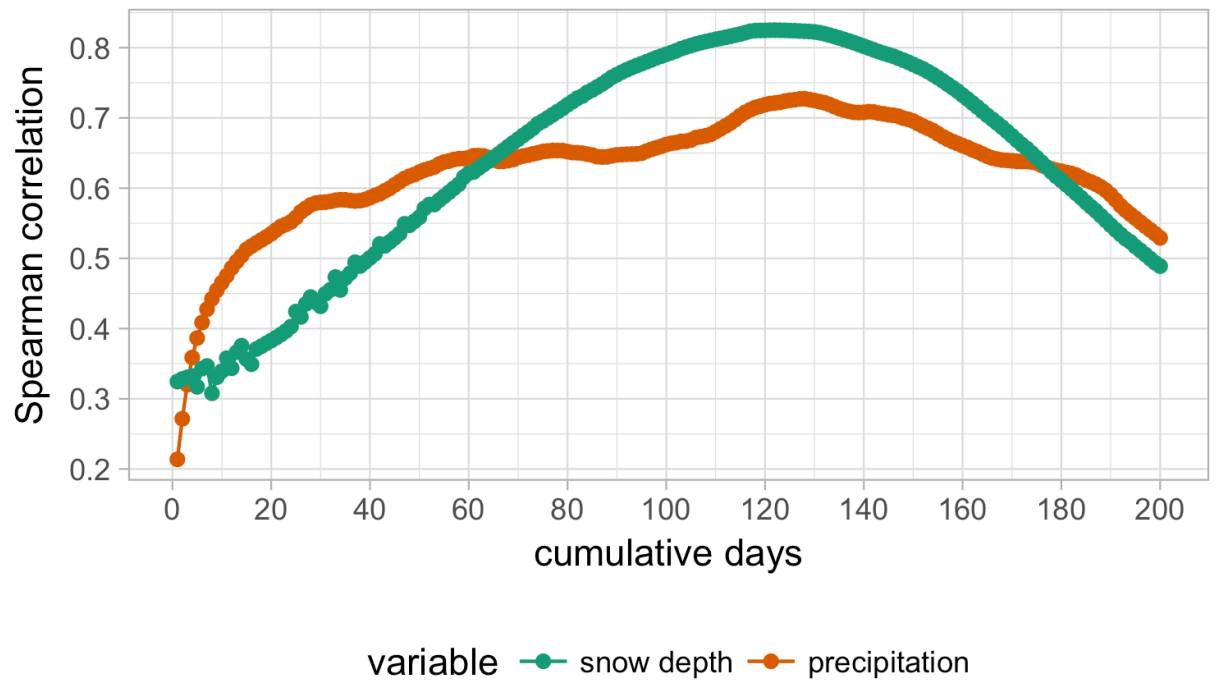

Figure 6: Spearman correlation between the French run-of-river daily generation (from January 2015 to June 2017) and snow depth and precipitation variables considering their cumulative sum for a period of $N$ days.

cumulated precipitation and snow depth for a varying number of days ranging from 0 to 200. In this particular case, the correlation maximum is obtained for an accumulation period of around 120 days, for both precipitation $(N)$ and snow cover $(M)$.

The model has been applied to all the available daily generation data for all the countries with a significant installed capacity of hydro-power. The list of the selected countries can be found in Table 1.

The capacity factor has been computed dividing the actual mean daily generation by the installed capacity for 2017. For some countries (Spain and Norway run-of-river), we can see that its value is greater than one, caused by inconsistencies in the dataset, probably due to the installed capacity lower than the actual considered in the generation data set. However, while we expect to have this issue solved in the next releases of the Transparency Platform, it does not affect the results presented in this paper because we focus our results on the relative changes instead of absolute values.

The methodology has been applied separately on run-of-river and reservoir capacity factors for each country. Figure 7 summarises for all the considered countries the values of the window chosen to cumulate precipitation 


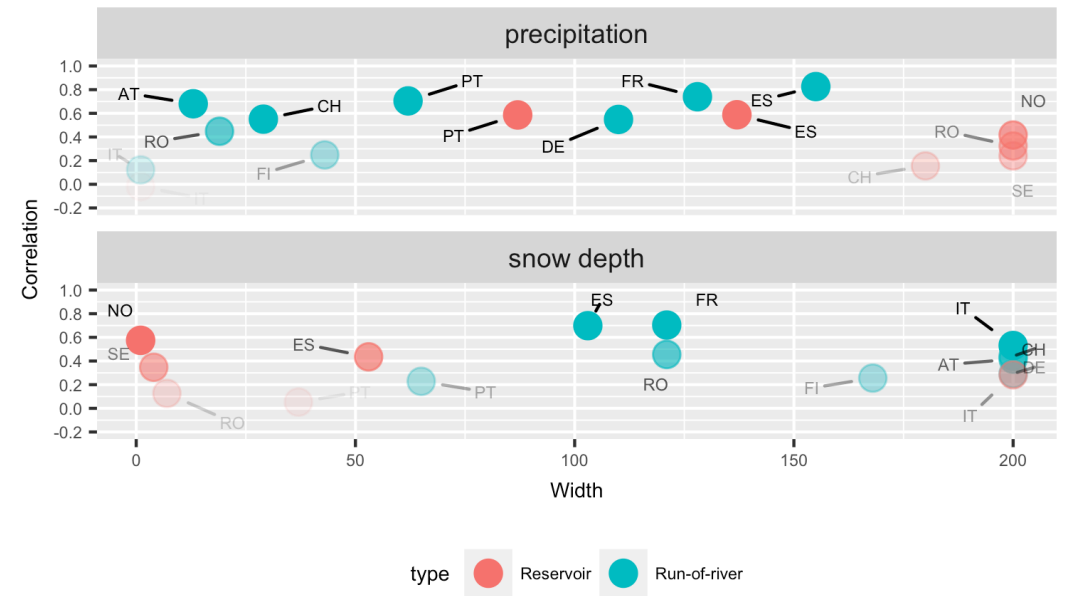

Figure 7: Width of the window used for the cumulated precipitation $(N)$ and snow depth $(M)$ for all the considered countries and the two typologies of hydro-power. To highlight the most significant points, the transparency of the points is inversely proportional to the value of the correlation.

$(N)$ and snow-depth $(M)$, and the value of the maximum correlation for both run-of-river and reservoir generation. In general, we can observe that run-ofriver shows the highest sensitivity to both of these predictors. This can be explained by the more direct relationship between weather and generation due to the absence of storage.

\subsection{Accuracy of the modelling with Random Forests}

As explained before, the RF model provides a robust way to building a long-term homogeneous data set of hydro-power capacity factor. It is however very important to assess its capability to reproduce the characteristics of the observed capacity factor time-series. Figure 8 presents the Spearman correlation coefficients between observed capacity factor and the out-of-bag output $^{10}$ from RF model for all the countries considered in this analysis, evidencing also the hydro-power installed capacity (the same shown in Figure 1).

It is evident how in general modelling run-of-river yields better skill than

\footnotetext{
${ }^{10}$ The out-of-bag estimation is computed averaging for each sample all the outputs of the trees which have not been used in the input training, for further details see [31].
} 


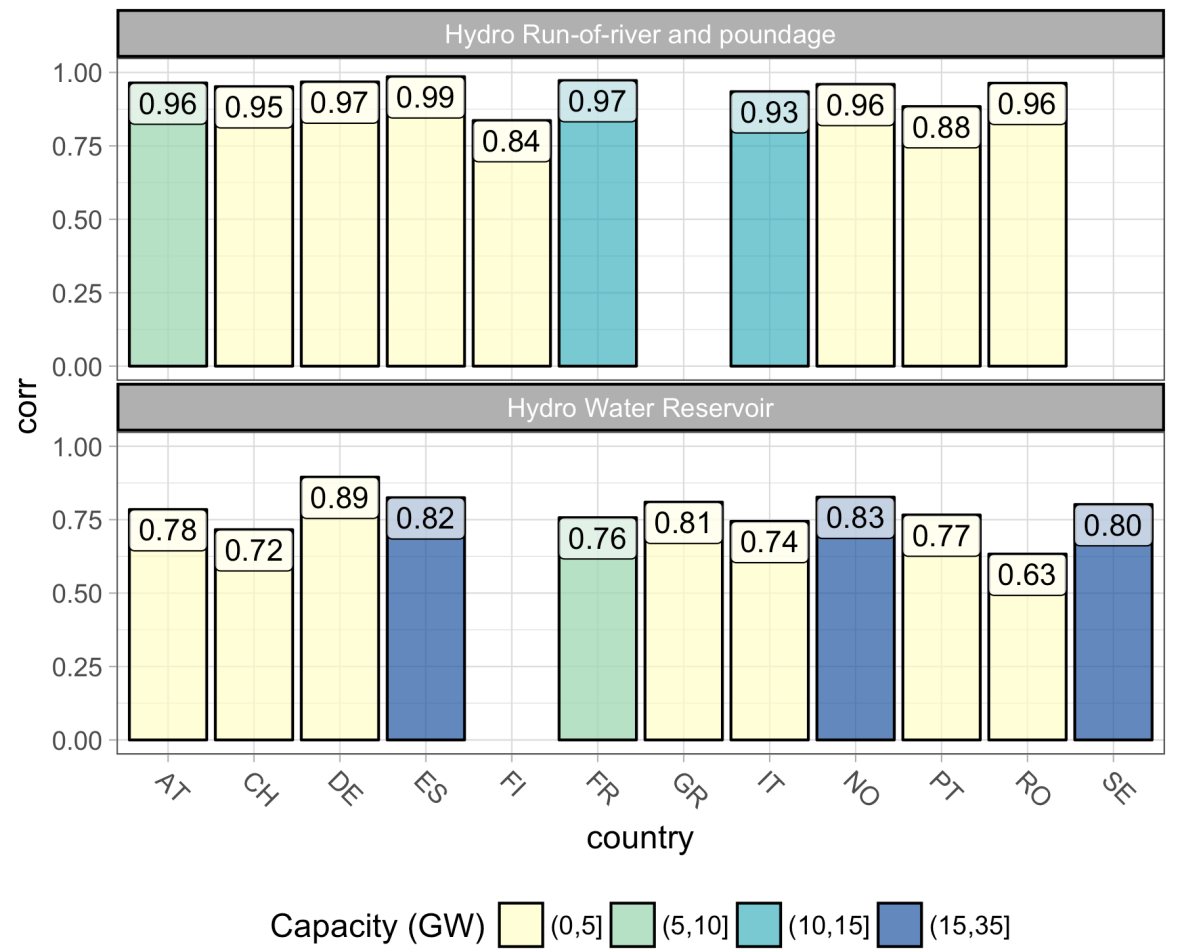

Figure 8: Spearman correlation between the out-of-bag Random Forests output and the actual hydro-power generation for the selected countries and the hydro-power typologies. The color of the bars represents the amount of hydro-power installed capacity (in GW). 


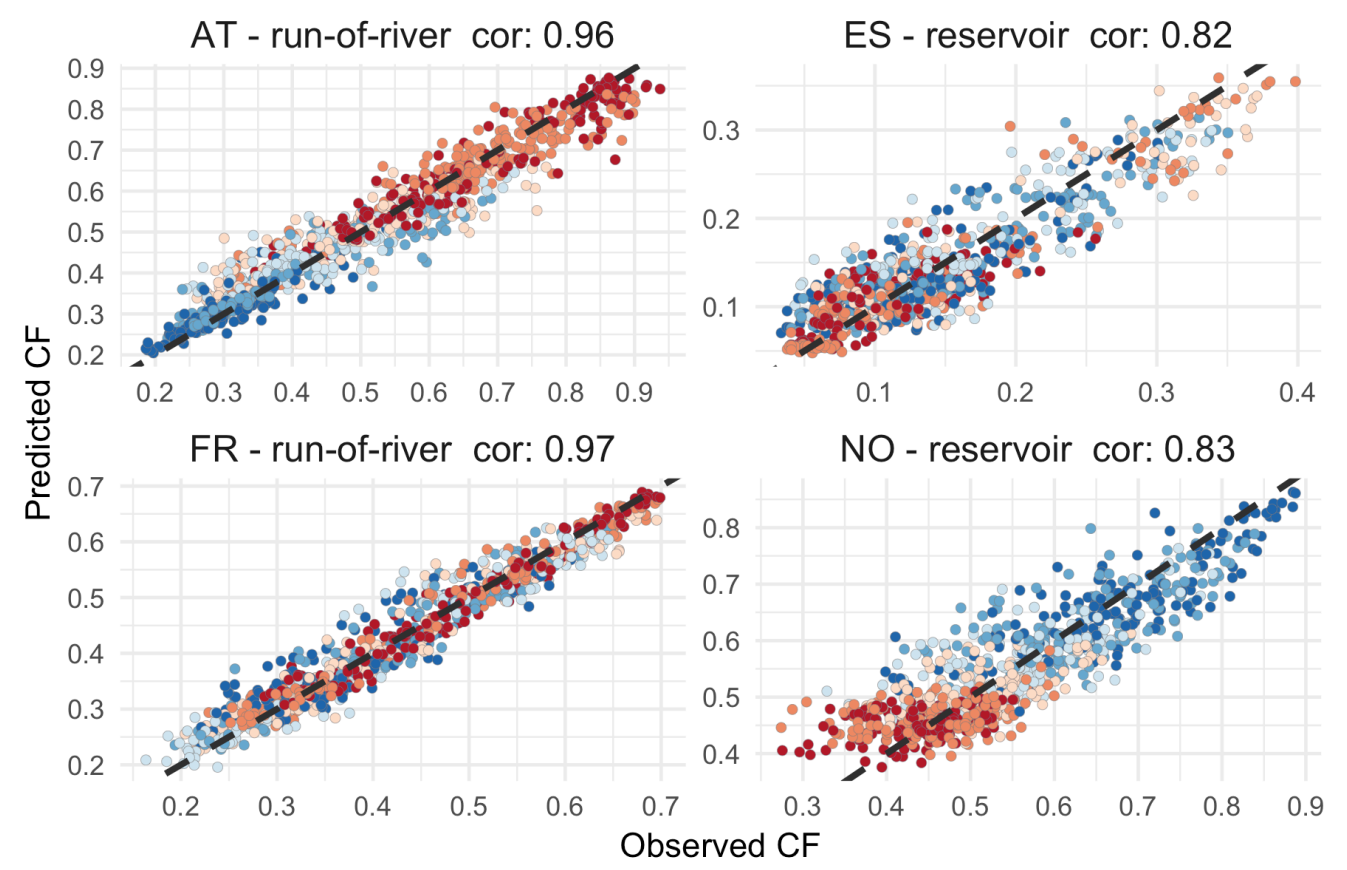

Figure 9: Scatter plot (with the correlation value) of the out-of-bag Random Forests output and the actual capacity factor for selected countries considering both run-of-river and reservoir. The color represents the period of the year: red shades are for the summer months and blue for the winter ones.

modelling reservoir generation. This is explained mainly by the fact that for run-of-river the connection between climate variables and generation is more direct given the absence of the storage and thus of the possibility to: 1) generate electricity when it is more convenient or useful; 2) use the water for different purposes (water supply, irrigation, etc.).

To assess the results in a different way, in the panels of Figure 9 we show the scatter plot for the countries with the high correlations and important installed capacity (greater than $5 \mathrm{GW}$ ) obtained with the Random Forests' modelling.

The scatter plot confirms that the run-of-river modelling seems quite effective, showing a very good accuracy all the year. For the Austrian runof-river, we can observe a tendency in underestimating when the capacity factor is high (greater than 0.6) and, vice versa, a tendency to overestimate when it is lower. In general we can see a similar tendency in all the four 
illustrated cases, perhaps suggesting that the model has some difficulties in predicting the extremes of the distribution. Moreover, this can be observed also comparing the accuracy during two seasons, summer and winter, in the case of Norwegian reservoir generation it is evident how during the summer months, when the capacity factor is lower, the model shows a very good accuracy: correlation during summer months is in fact 0.47 , while during winter is equal to 0.83 . In this case we can try to explain this difference considering that operation of reservoir hydro-power plant might vary a lot during the year accordingly to the availability of water and to other important factors like the cost of importing the electricity or the expected profit in exporting it.

As described previously, we then use the coefficients of the training model to extend the capacity factors time-series over the 1979-2017 for the selected countries for run-of-river and reservoir generation and using the climate variables from the full ERA-Interim period. This dataset underpins the study of the influence of the NAO on hydropower generation, as we illustrate in the following sections.

\section{The influence of large-scale patterns on hydro-power generation: North Atlantic Oscillation}

In this section we analyse the impact of the most important European large-scale weather pattern on hydro-power generation. The analysis is focused on the period 1979-2017 and it is based on the generation data produced with the approach described in the previous section.

\subsection{Impact on river flows and precipitation}

In this section, we investigate the relationship between NAO and a set of meteorological variables that can be linked to hydropower generation modelling: temperature, precipitation and snow depth.

We focus on the differences between the years with the winter NAO in a positive phase (i.e. index greater than 0.5 ) and a negative phase (i.e. index lower than -0.5). The annual values have been calculated using a hydrological year, i.e. the period between October and September.

Figures 10-12 show the difference of the annual values of precipitation (Fig. 10), air temperature (Fig. 11) and snow depth (Fig. 12) between the years with a winter NAO in its positive and negative phase. For each variable we compute the average value in the hydrological years according to the NAO 
phase and then we show the difference, applying a Kolmogorov-Smirnov test to estimate the significance of the difference.

The three figures shows the classic scenario associated to the North Atlantic Oscillation phases: when it is positive we have in general a warmer year in the northern part of Europe (see Fig. 11) and less precipitation in the Mediterranean area (Fig. 10), in particular in the Iberian peninsula. The positive phase also leads to less snow in the Alps, in the Carpathians and in the Scandinavian region (Fig. 12).

The difference in precipitation is particularly marked in the Mediterranean area, where the total annual precipitation is in average lower than 300 $\mathrm{mm}$. In fact, if we look at the percentage change during the NAO positive years we have a reduction of about $20 \%$ in the Southern Italy and between $-30 \%$ and $-60 \%$ in the lowest part of the Iberian Peninsula. On the other hand, in the Norwegian coasts the annual precipitation is normally above $600 \mathrm{~mm}$ with an increase in the NAO positive years of about $+15 \%$.

In the following sections we show how this change affects the generation of hydro-power generation, both for run-of-river (Section 4.2) and reservoirbased (Section 4.3).

\subsection{NAO impact on run-of-river hydro-power generation}

We have illustrated how the value of the NAO index is related to the patterns of meteorological variables over Europe. In this part, using the generation data produced using the approach described in Section 3, we can analyse how the NAO is linked to the patterns of run-of-river generation in the European countries.

Figure 13 shows the percentage change of the average capacity factor during the hydrological year between the years with winter NAO in positive and negative. We can see how some of the changes are consistent with the pattern illustrated in Section 4.1, especially with the changes in precipitation (Fig. 10): the Iberian peninsula shows a clear link with the phase of NAO (especially in Portugal where the change is $-7.5 \%$ ), as well as Italy with a change of $-5.1 \%$.

For a more detailed investigation of the differences between the two NAO states, in Figure 14 we can see the distribution of all the yearly capacity factors for run-of-river generation highlighting the NAO positive (HIGH) and negative (LOW) phases. We can observe how many countries, consistently with what is shown in Figure 13, a positive NAO leads to a significantly lower capacity factor. Figure 15 shows instead time-series of the daily capacity 


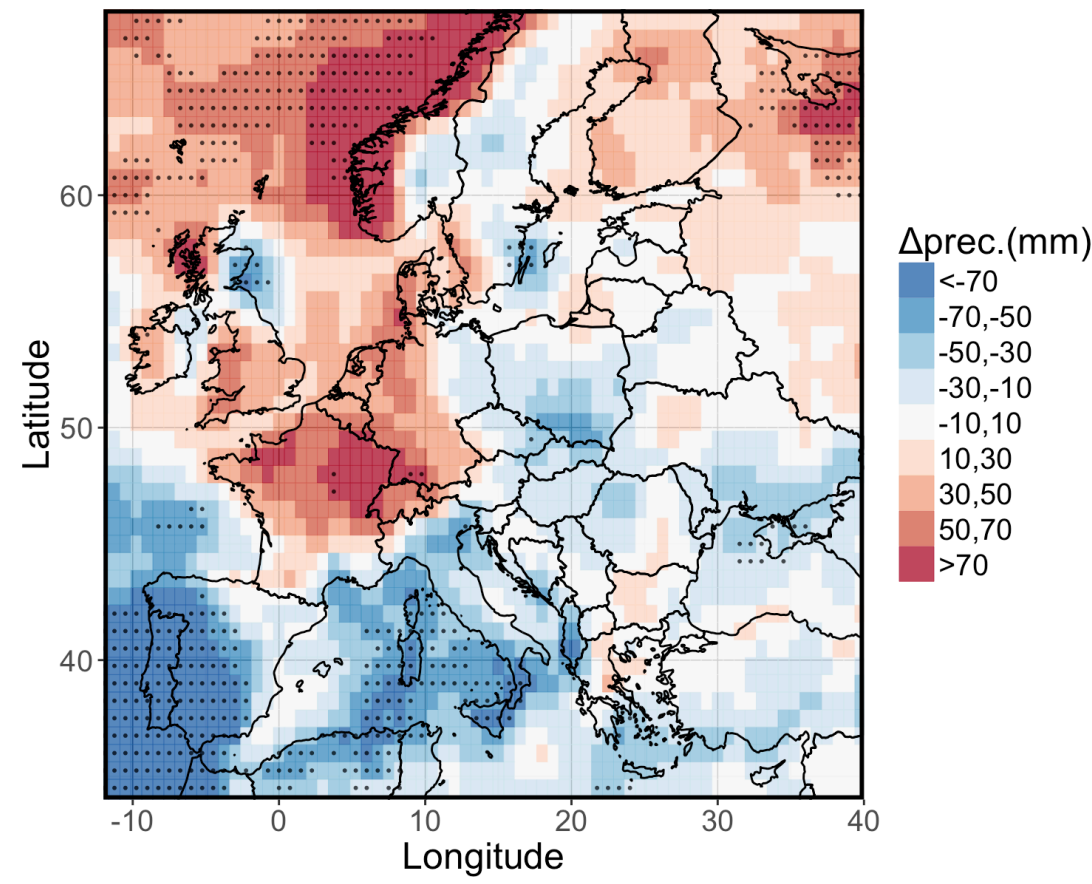

Figure 10: difference (in $\mathrm{mm}$ ) in annual cumulated precipitation between the years with positive winter NAO (i.e. $\mathrm{NAO}>0.5)$ and with negative winter $\mathrm{NAO}(\mathrm{NAO}<-0.5)$. The annual values have been calculated using a hydrological year, i.e. the period between October and September. Dotted grid points represent the areas where the difference between the two values is statistically significant using a two-sample Kolmogorov-Smirnov test and p-value of 0.05 


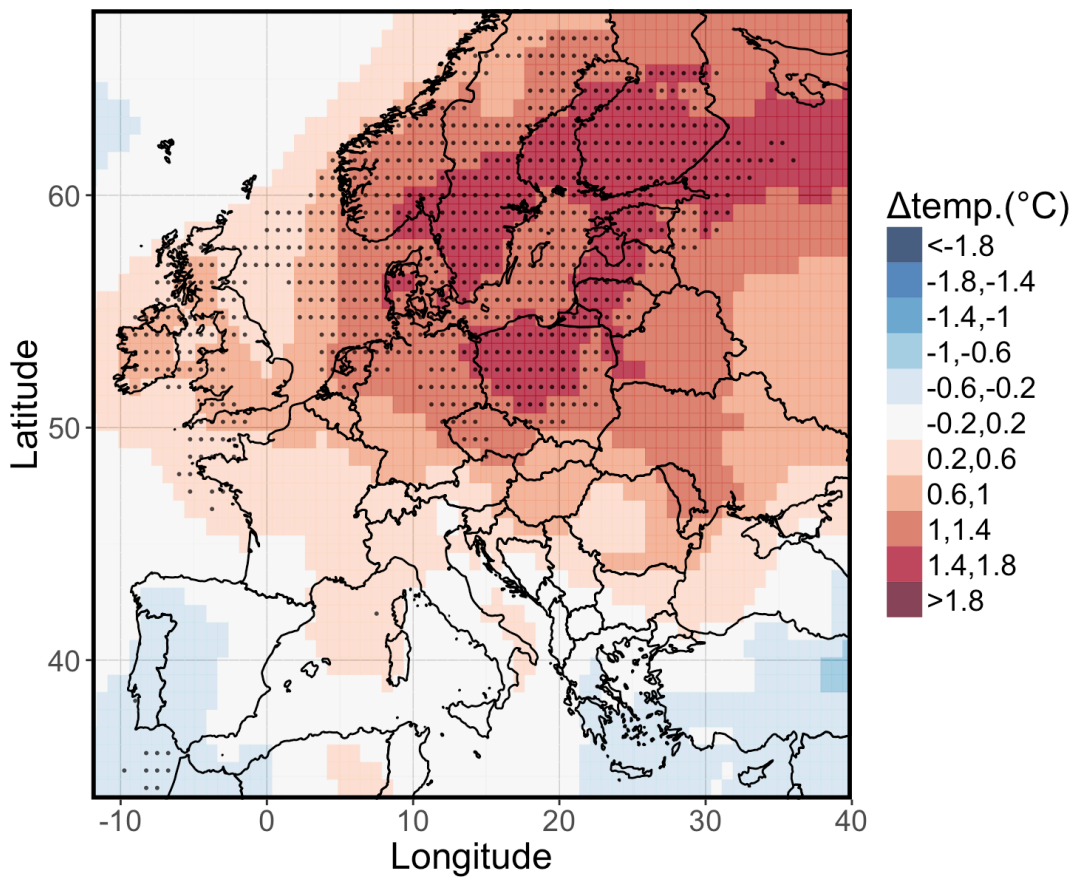

Figure 11: difference (in Celsius degrees) in annual mean temperature between the years with positive winter NAO (i.e. $\mathrm{NAO}>0.5)$ and with negative winter NAO $(\mathrm{NAO}<-0.5)$. The annual values have been calculated using a hydrological year, i.e. the period between October and September. Dotted grid points represent the areas where the difference between the two values is statistically significant using a two-sample Kolmogorov-Smirnov test and p-value of 0.05 


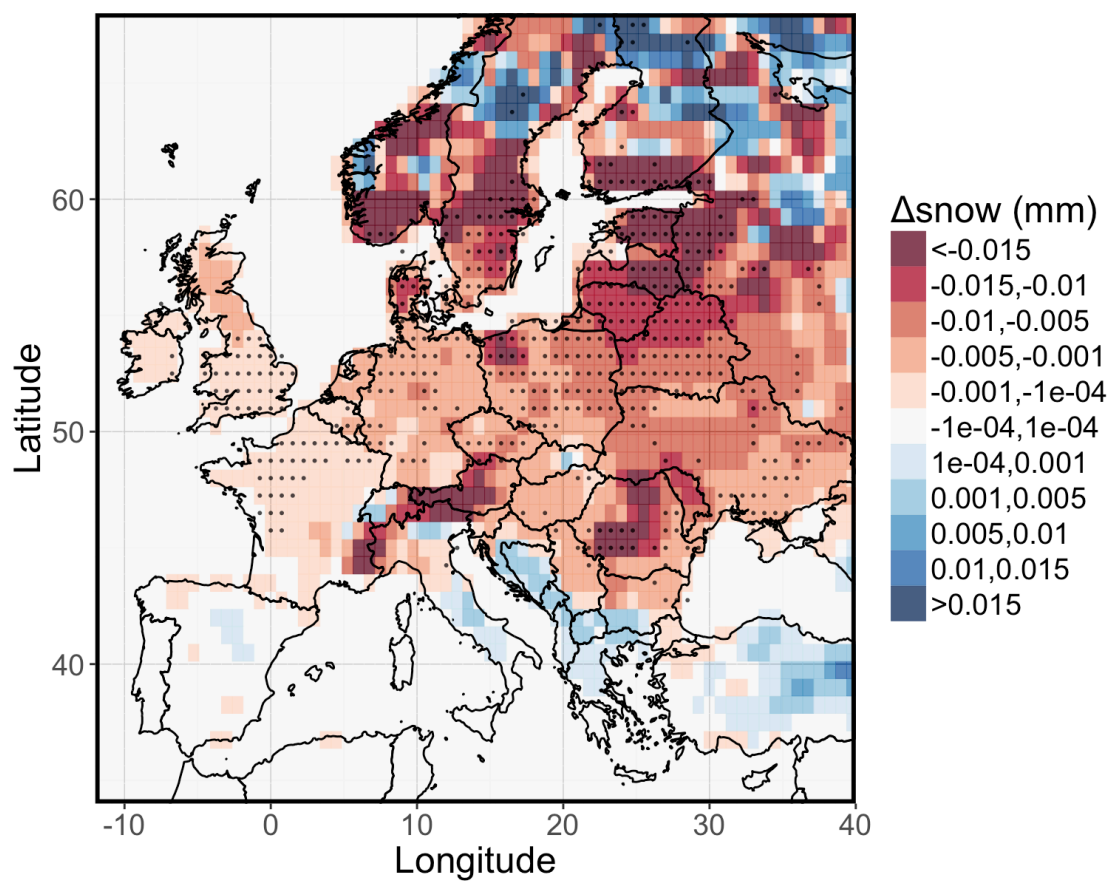

Figure 12: difference $(\mathrm{mm})$ in annual mean snow depth between the years with positive winter NAO (i.e. NAO $>0.5)$ and with negative winter $\mathrm{NAO}(\mathrm{NAO}<-0.5)$. The annual values have been calculated using a hydrological year, i.e. the period between October and September. Dotted grid points represent the areas where the difference between the two values is statistically significant using a two-sample Kolmogorov-Smirnov test and p-value of 0.05 


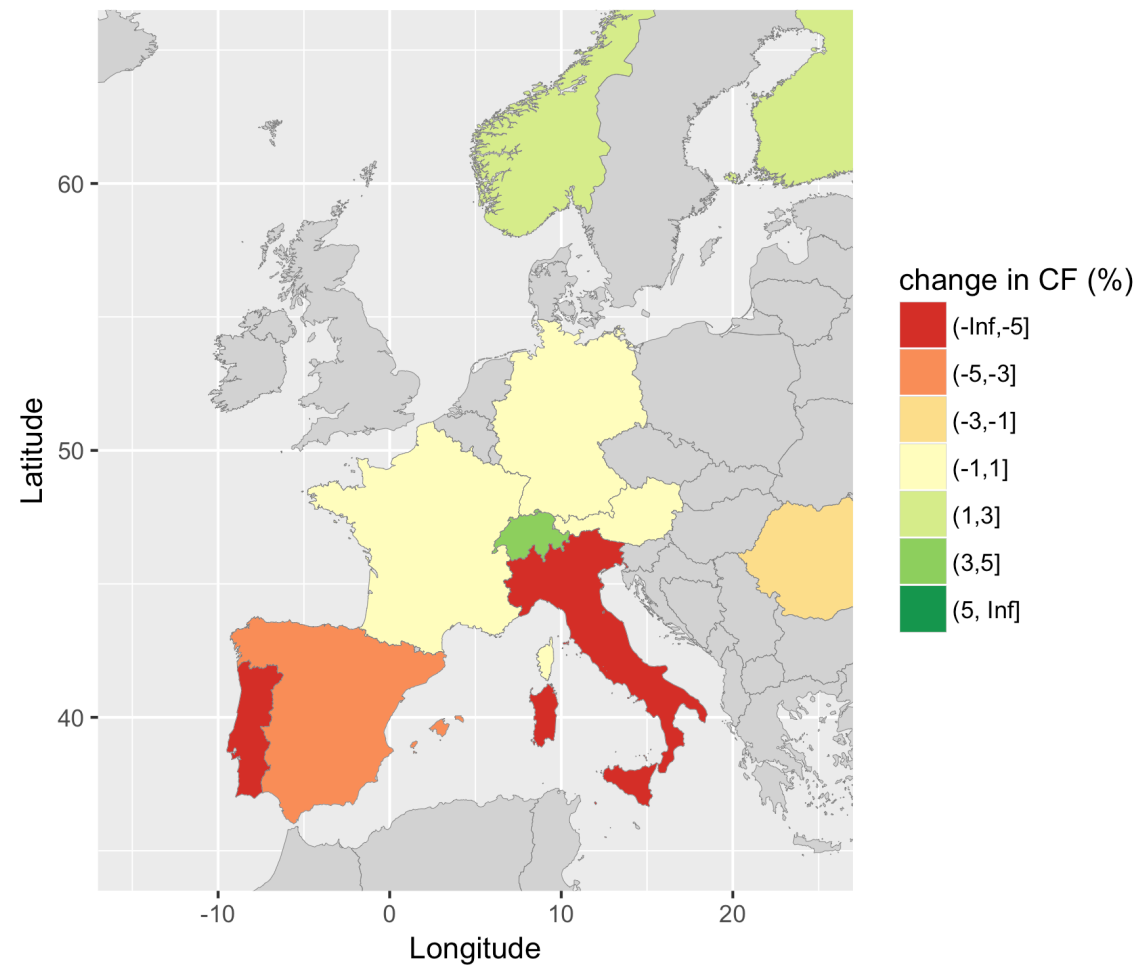

Figure 13: Percentage change in annual mean capacity factor for run-of-river generation between the years with positive winter NAO (i.e. NAO $>0.5$ ) and with negative winter NAO $(\mathrm{NAO}<-0.5)$. The annual values have been calculated using a hydrological year, i.e. the period between October and September. 


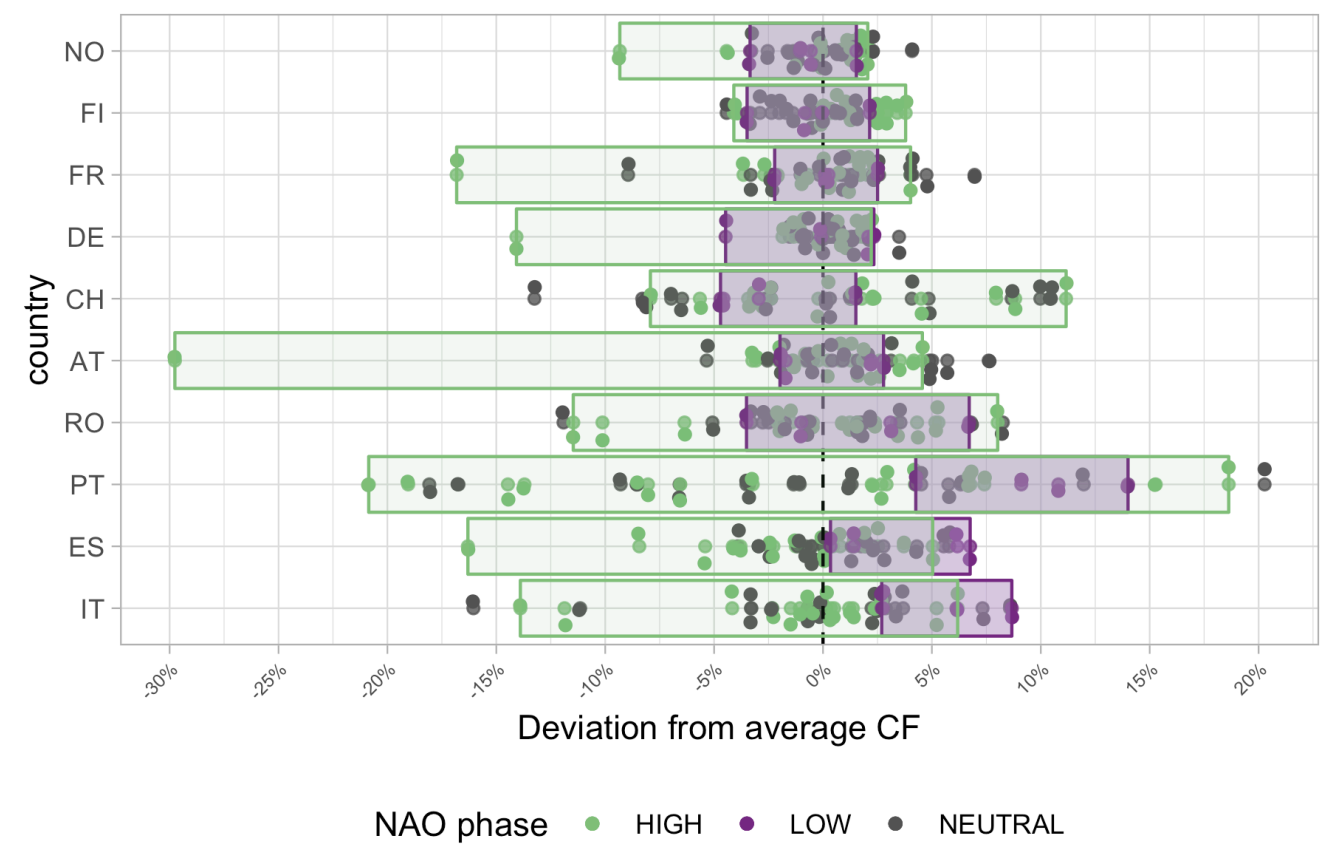

Figure 14: Distribution of the annual run-of-river capacity factors of the hydrological years according to the phase of the winter NAO. The boxes highlight the range of the CFs for the NAO positive and negative phases. The countries have been ordered according to their latitude to show how the effect of negative NAO is more evident in the Southern Europe.

factor for the years when the NAO was in a positive phase (red lines) and in a negative phase (blue lines). Moreover, a locally weighted smoothing (LOESS) is also shown to summarise the two groups.

In figures 14 and 15, we observe how the NAO phase affects the hydropower generation in the Iberian peninsula, in Portugal impacting evidently the first four months of the year while in Spain reducing the generation almost constantly all the year. Finally, as suggested by Figure 13, the Scandinavian countries show an increase during the NAO positive phase due to the "wet" pattern in the northern Europe typical of the positive phase.

\subsection{Impact on reservoir hydro-power generation}

Similarly to Section 4.2 , in this part we can analyse how the NAO is able to describe the patterns of reservoir generation in the European countries.

In figure 16 we present the change of the average $\mathrm{CF}$ for reservoir generation during the hydrological year between the years with winter NAO in 

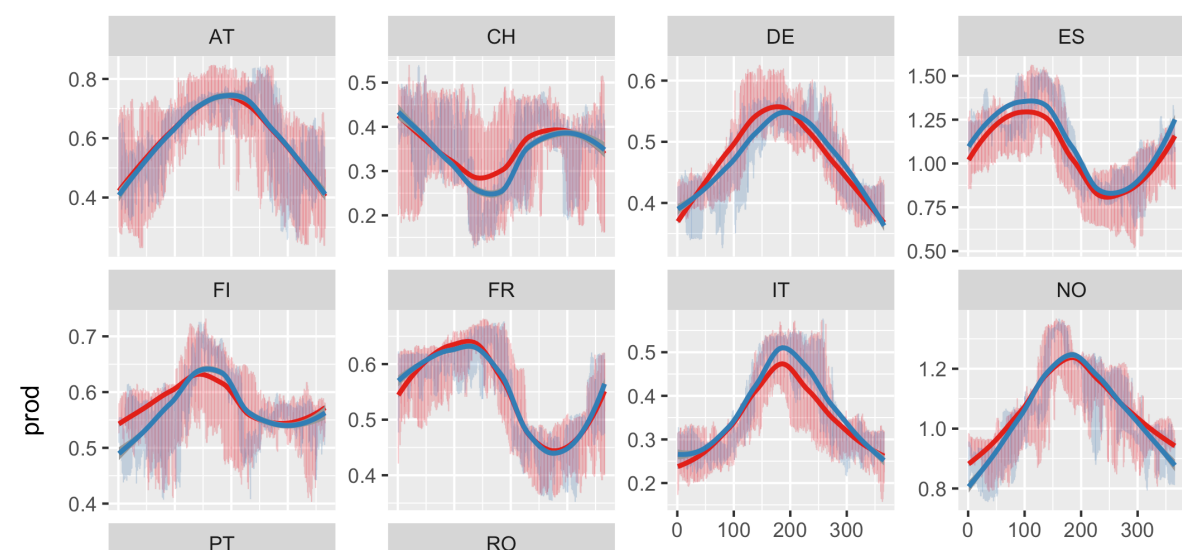

NAO
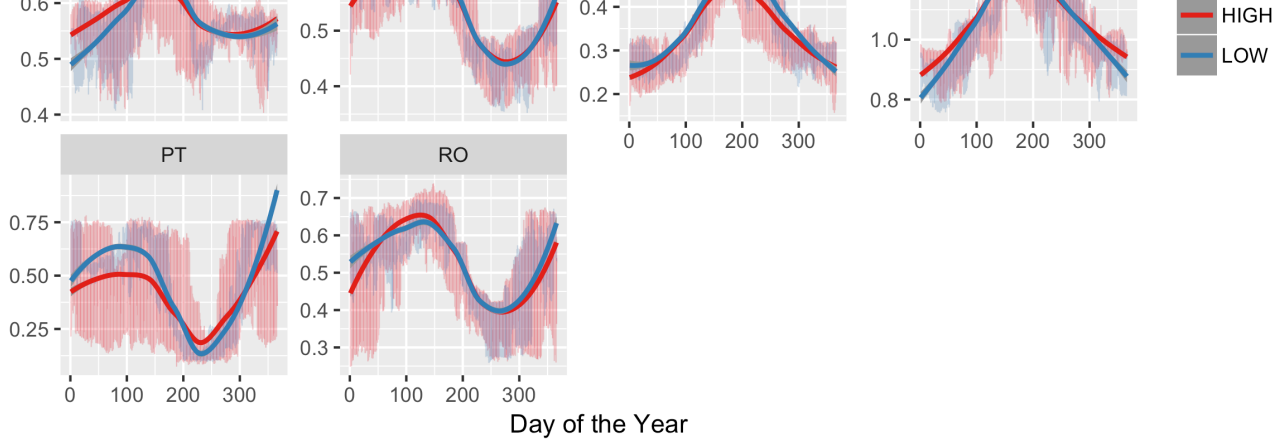

Figure 15: Time-series of the run-of-river capacity factor grouped by the kernel density estimation of the daily run-of-river capacity factors of the hydrological years according to the phase of the Winter NAO. Only positive (i.e. NAO $>0.5$, light red) and negative $(\mathrm{NAO}<-0.5$, light blue) have been considered. For each phase a LOESS estimator has been applied to highlight the difference between the two phases. 


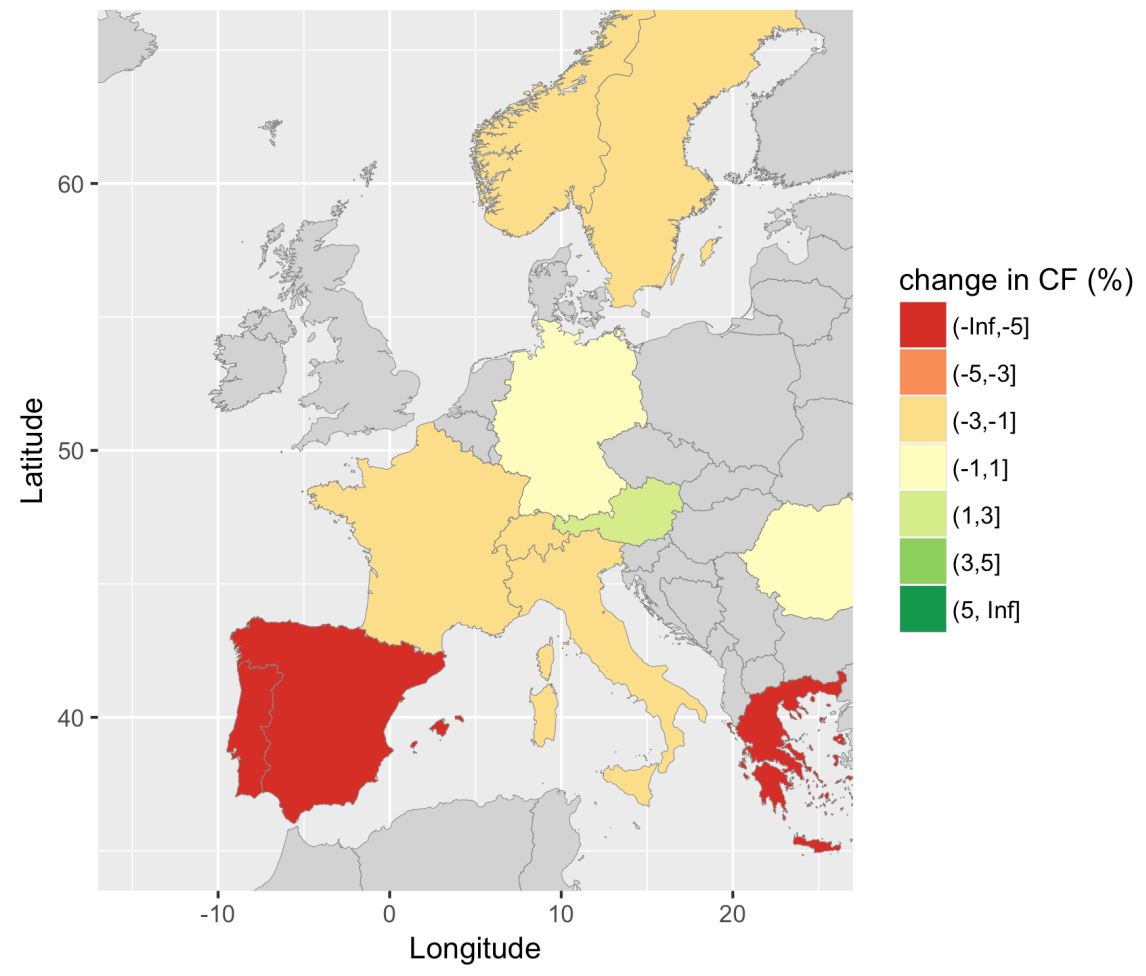

Figure 16: Percentage change in annual mean capacity factor for reservoir generation between the years with positive winter NAO (i.e. NAO > 0.5) and with negative winter $\mathrm{NAO}(\mathrm{NAO}<-0.5)$. The annual values have been calculated using a hydrological year, i.e. the period between October and September.

positive and negative phases (both considered using the threshold, respectively, of +0.5 and -0.5$)$.

The changes shown in the map are again consistent with the pattern illustrated in Figure 10, and the percentage change is consistently negative for all the countries considered, except for Germany and Romania which do not show a significant change.

Finally, for a more detailed investigation of the differences between the two NAO states, in Figure 17 we can see the difference between NAO positive (HIGH) and negative (LOW) of the annual capacity factor and in Figure 18 a locally weighted smoothing (LOESS) applied on daily capacity-factor timeseries grouped by the phase of the winter NAO.

The figures depict a varied scenario where, in general, most of the coun- 


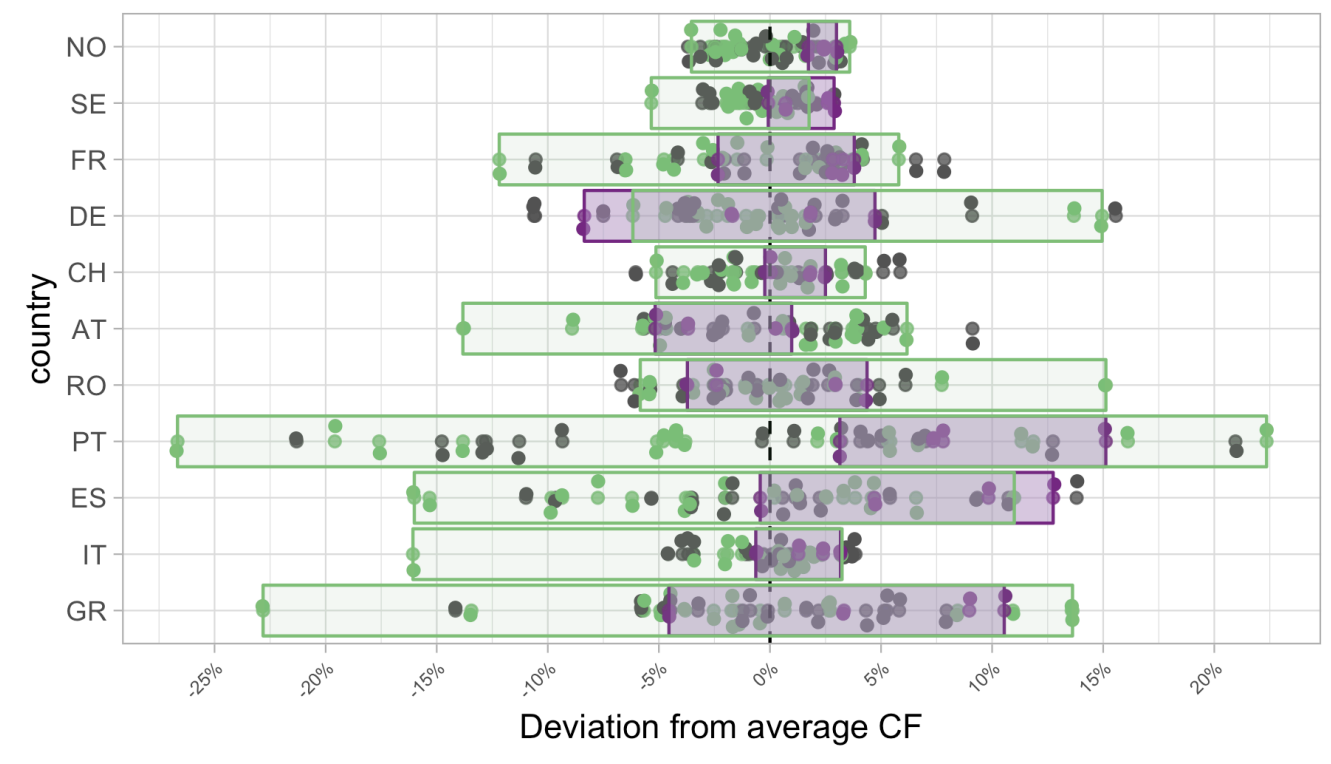

NAO phase $\bullet \mathrm{HIGH} \bullet$ LOW $\bullet$ NEUTRAL

Figure 17: Distribution of the annual reservoir capacity factors of the hydrological years according to the phase of the winter NAO. The boxes highlight the range of the CFs for the NAO positive and negative phases. The countries have been ordered according to their latitude to show how the effect of negative NAO is more evident in the Southern Europe. 

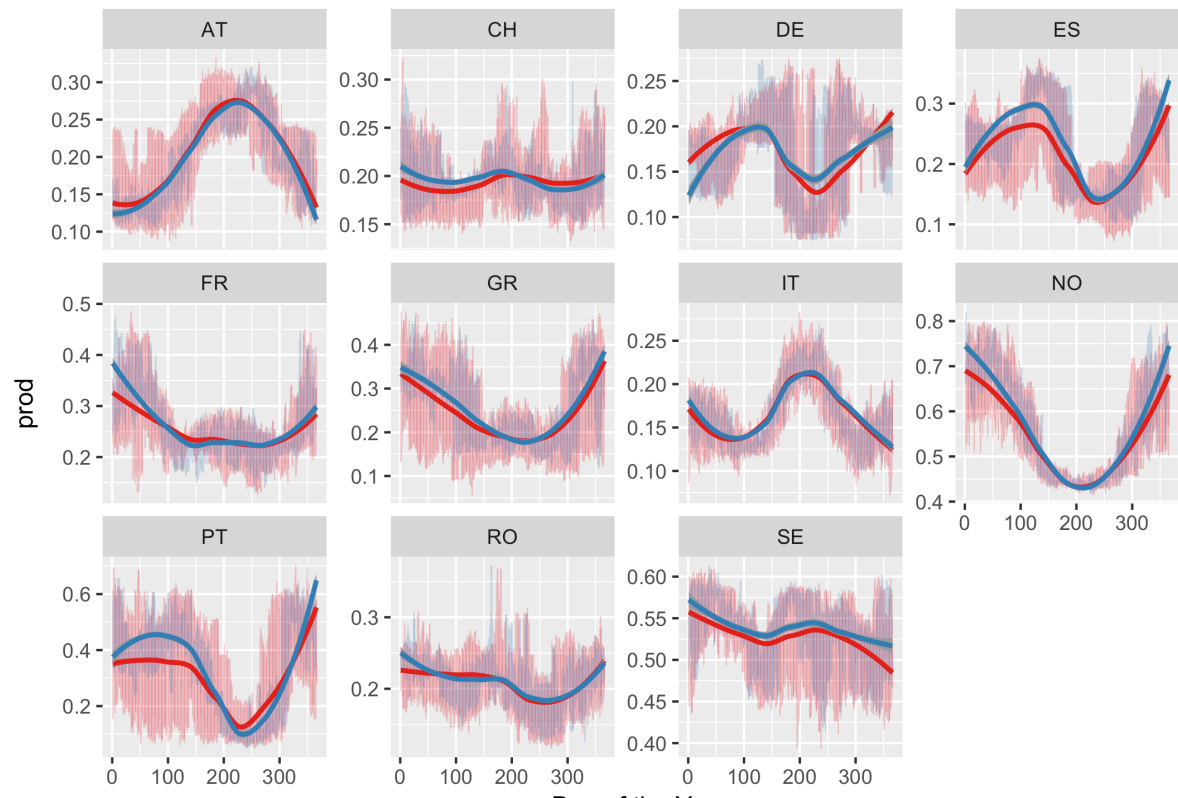

NAO
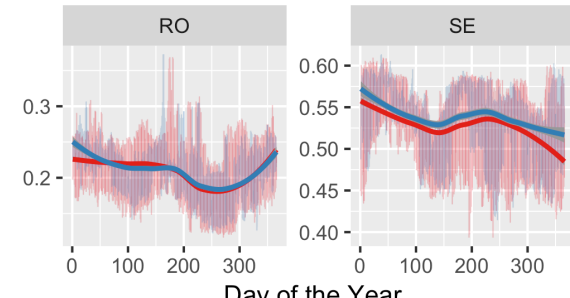

- HIGH

Figure 18: Time-series of the run-of-river capacity factor grouped by the kernel density estimation of the daily run-of-river capacity factors of the hydrological years according to the phase of the Winter NAO. Only positive (i.e. NAO $>0.5$, light red) and negative $(\mathrm{NAO}<-0.5$, light blue) have been considered. For each phase a LOESS estimator has been applied to highlight the difference between the two phases. 


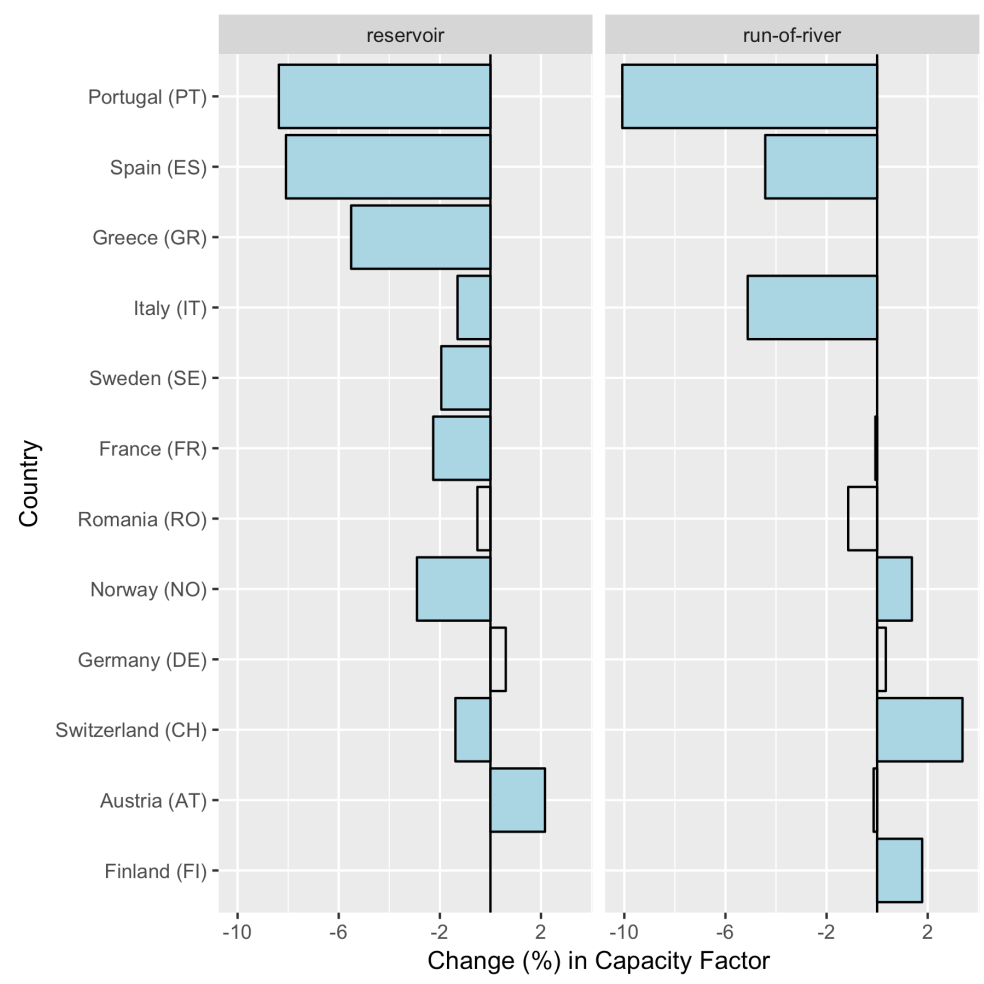

Figure 19: Percentage change (NAO positive minus NAO negative) in annual capacity factors for both the typologies of hydro-power between the hydrological years with positive and negative winter NAO phases. Filled bars represent the changes that can be considered statistically significant using a Welch two-sample t-test with a p-value of 0.05.

tries show a reduction of the generation but in different parts of the year and with a different intensity. In the Iberian Peninsula the change patterns are similar to what is observed for run-of-river generation. The German generation shows instead a dual change, positive during winter and early spring and negative during summer

\subsection{Discussion of the results}

An overview of the changes in generation for both the typologies of hydropower can be seen in 19 where for all the countries considered here. The figure summarises the percentage change of the CF during NAO positive years minus the $\mathrm{CF}$ during the years with a negative phase.

It is important to note the main difference between run-of-river and reservoir generation: as stated in Section 3.2, the observed reservoir generation 
includes also the management of the reservoir, making less direct the link between the water availability and electricity production. However, as shown here, when we look at the yearly averages we can observe significant changes for both the typologies.

As suggested by the analysis of the meteorological patterns in Section 4 and in agreement with works present in scientific literature (see [27] and [28]), the Iberian Peninsula is the region which experiences the clearest connection with the NAO phases. According to the ENTSO-E Transparency Platform, in this region there are about $25 \mathrm{GW}$ of installed capacity of run-of-river and reservoir-based hydro-power, this means that about $20 \%$ of the total installed generation capacity is affected by a large-scale meteorological pattern such as the NAO.

Not surprisingly, we can observe how the entire Mediterranean area (including southern France, where the majority of the French hydro-power plants are located) is clearly linked with NAO variability. Considering the inter-connectivity of the power grids of the affected countries, this is a phenomenon that should be taken into account when considering how climate can impact the energy sector in southern Europe.

\section{Conclusions}

This work investigates the impact of North Atlantic Oscillation (NAO) pattern on European hydro-power generation. The novelty of the work lies in the use of a synthetic 39-year dataset of hydro-power generation created with a machine-learning model fitted on the latest three years of observed generation. This dataset ${ }^{11}$ allows to analyse the link between meteorology and hydro-power at European level in a homogeneous and statistically robust way. Most of the results are consistent with the findings of previous research, and this is the first time that the major hydropower European countries are looked at once thanks to the extensive data set produced. This gives us the possibility to have a better understanding of the dynamics of the European power networks. This was one of the aims of the C3S ECEM proof-of-concept and this paper represents a clear example of the possibilities in having a consistent dataset of energy variables for all the European countries.

\footnotetext{
${ }^{11}$ Accessible at the following URL: http://ecem.climate.copernicus.eu/ demonstrator/
} 
The NAO has been selected for two main reasons: 1) it is a large-scale pattern known to have an influence on many European countries and; 2) the NAO index shows some predictability at seasonal time-scales (i.e. 1-3 months ahead)

The results have shown how the NAO, which is known to have a significant impact on temperature and precipitation on the European continent, can be also linked to hydro-power generation, both for run-of-river and reservoir generation. The generation data for all the countries considered in this study exhibit to some extent a clear relationship with the NAO phase: in general we observe that a positive NAO leads to a reduction of the hydro-power generation in southern Europe. This means that during the strongest positive NAO phases those countries should rely more on other sources or on the exchange with the neighbouring countries to satisfy their electricity needs. This can potentially expose the national power systems to adequacy issues in case of the co-occurrence of other events impacting the generation and cross-border exchange (for example high temperatures or low PV/wind power production).

Moreover, considering a low-carbon future where the penetration of renewable energies like wind and solar power is likely to increase, hydro-power plays a critical role thanks to its flexibility and capability to assure the balancing. In this scenario, the analysis proposed in this paper together with an assessment on the co-variability of energy sources (as for example it has been done in [32]) is of critical importance to investigate the robustness of the European power networks to large-scale weather patterns.

As we stated before, strong NAO phases (both positive and negative) could have a stronger impact when other energy sources (e.g. wind or solar) or the electricity demand show a clear variation from the usual values. In those cases, to maintain the grid balances and to have an efficient supply of energy, it could be of critical importance to have an estimation a season (i.e. 1-3 months) ahead about the NAO index (for example see [23] where seasonal forecasts are used to improve the management of hydropower production). To this end, it is worth noting the improvement in the last years of the European seasonal climate forecasting systems, in fact recent studies have reported skill at predicting winter NAO from seasonal forecasts using dynamical models [33]. Evidence of teleconnections between winter NAO and European climate in the following spring have also been suggested based on statistical analyses using observations [34].

Moreover, additional climatic drivers of hydro-power might be predictable 
to some extent, giving then the possibility to refine any generation forecast based on the NAO index. For example, hydro-power generation in the Iberian Peninsula is also affected by the El Niño Southern Oscillation (ENSO) [4] which is predictable at seasonal time-scales [35].

As explained in Section 1.2, there are multiple scientific works investigating the influence of the NAO on the European energy systems. The analysis

on the impact of NAO on national energy mixes based on the renewable energy data generated by C3S ECEM is left as future work.

\section{Acknowledgements}

The authors and their institutions (ENEA, EDF, University of Reading, University of East Anglia) would like to acknowledge funding for the European Climatic Energy Mixes (ECEM) service by the Copernicus Climate Change Service (C3S), a programme being implemented by the European Centre for Medium-Range Weather Forecasts (ECMWF) on behalf of the European Commission. 
[1] European Environment Agency, Renewable energy in Europe 2017, Technical Report 3, EEA Report, 2017.

[2] IRENA, Renewable power generation costs in 2014, 2014.

[3] L. Dubus, Weather and climate and the power sector: Needs, recent developments and challenges, in: Weather matters for energy, Springer, 2014, pp. 379-398.

[4] J. Y. Ng, S. W. Turner, S. Galelli, Influence of el niño southern oscillation on global hydropower production, Environmental Research Letters 12 (2017) 034010.

[5] J. W. Hurrell, H. Van Loon, Decadal variations in climate associated with the north atlantic oscillation, in: Climatic Change at High Elevation Sites, Springer, 1997, pp. 69-94.

[6] C. Appenzeller, T. Stocker, M. Anklin, North Atlantic Oscillation dynamics recorded in Greenland ice cores, Science 282 (1998) 446-449.

[7] H. Steptoe, S. Jones, H. Fox, Correlations between extreme atmospheric hazards and global teleconnections: Implications for multihazard resilience, Reviews of Geophysics 56 (2018) 50-78.

[8] E. Steirou, L. Gerlitz, H. Apel, B. Merz, Links between large-scale circulation patterns and streamflow in central europe: A review, Journal of Hydrology 549 (2017) 484-500.

[9] E. J. Palin, A. A. Scaife, E. Wallace, E. C. Pope, A. Arribas, A. Brookshaw, Skillful seasonal forecasts of winter disruption to the UK transport system, Journal of Applied Meteorology and Climatology 55 (2016) 325-344.

[10] D. Pozo-Vazquez, F. J. Santos-Alamillos, V. Lara-Fanego, J. A. RuizArias, J. Tovar-Pescador, The impact of the nao on the solar and wind energy resources in the mediterranean area, in: Hydrological, Socioeconomic and Ecological Impacts of the North Atlantic Oscillation in the Mediterranean Region, Springer, 2011, pp. 213-231.

[11] D. J. Brayshaw, A. Troccoli, R. Fordham, J. Methven, The impact of large scale atmospheric circulation patterns on wind power generation 
and its potential predictability: a case study over the UK, Renewable Energy 36 (2011) 2087-2096.

[12] J. W. Hurrell, Decadal trends in the north atlantic oscillation: regional temperatures and precipitation, Science 269 (1995) 676-679.

[13] T. J. Osborn, Winter 2009/2010 temperatures and a record-breaking north atlantic oscillation index, Weather 66 (2011) 19-21.

[14] P. Jones, T. Jonsson, D. Wheeler, Extension to the north atlantic oscillation using early instrumental pressure observations from gibraltar and south-west iceland, International Journal of Climatology: A Journal of the Royal Meteorological Society 17 (1997) 1433-1450.

[15] A. A. Scaife, J. R. Knight, G. K. Vallis, C. K. Folland, A stratospheric influence on the winter NAO and North Atlantic surface climate, Geophysical Research Letters 32 (2005).

[16] S. Ineson, A. Scaife, The role of the stratosphere in the european climate response to el niño, Nature Geoscience 2 (2009) 32.

[17] K. Matthes, Y. Kuroda, K. Kodera, U. Langematz, Transfer of the solar signal from the stratosphere to the troposphere: Northern winter, Journal of Geophysical Research: Atmospheres 111 (2006).

[18] R. Seager, Y. Kushnir, J. Nakamura, M. Ting, N. Naik, Northern hemisphere winter snow anomalies: Enso, nao and the winter of 2009/10, Geophysical research letters 37 (2010).

[19] C. Wang, H. Liu, S.-K. Lee, The record-breaking cold temperatures during the winter of 2009/2010 in the northern hemisphere, Atmospheric Science Letters 11 (2010) 161-168.

[20] S. M. Vicente-Serrano, R. M. Trigo, J. I. López-Moreno, M. L. Liberato, J. Lorenzo-Lacruz, S. Beguería, E. Morán-Tejeda, A. El Kenawy, Extreme winter precipitation in the iberian peninsula in 2010: anomalies, driving mechanisms and future projections, Climate Research 46 (2011) 51-65.

[21] L. Barker, J. Hannaford, K. Muchan, S. Turner, S. Parry, The winter 2015/2016 floods in the UK: a hydrological appraisal, Weather 71 (2016) 324-333. 
[22] W. Zhang, G. Villarini, On the unseasonal flooding over the central united states during december 2015 and january 2016, Atmospheric Research 196 (2017) 23-28.

[23] J. Engström, C. B. Uvo, Effect of northern hemisphere teleconnections on the hydropower production in southern Sweden, Journal of Water Resources Planning and Management 142 (2015) 05015008.

[24] C. B. Uvo, R. Berndtsson, North atlantic oscillation; a climatic indicator to predict hydropower availability in scandinavia, Hydrology Research 33 (2002) 415-424.

[25] J. Cherry, H. Cullen, M. Visbeck, A. Small, C. Uvo, Impacts of the North Atlantic Oscillation on Scandinavian hydropower production and energy markets, Water resources management 19 (2005) 673-691.

[26] B. François, Influence of winter north-atlantic oscillation on climaterelated-energy penetration in europe, Renewable Energy 99 (2016) 602-613.

[27] R. M. Trigo, D. Pozo-Vázquez, T. J. Osborn, Y. Castro-Díez, S. GámizFortis, M. J. Esteban-Parra, North atlantic oscillation influence on precipitation, river flow and water resources in the iberian peninsula, International Journal of Climatology 24 (2004) 925-944.

[28] S. Jerez, R. Trigo, S. M. Vicente-Serrano, D. Pozo-Vázquez, R. LorentePlazas, J. Lorenzo-Lacruz, F. Santos-Alamillos, J. Montávez, The impact of the north atlantic oscillation on renewable energy resources in southwestern europe, Journal of applied meteorology and climatology 52 (2013) 2204-2225.

[29] L. Hirth, J. Mühlenpfordt, M. Bulkeley, The ENTSO-E Transparency Platform-A review of Europe's most ambitious electricity data platform, Applied Energy 225 (2018) 1054-1067.

[30] L. Breiman, Random forests, Machine learning 45 (2001) 5-32.

[31] J. Friedman, T. Hastie, R. Tibshirani, The elements of statistical learning, volume 1, Springer series in statistics New York, NY, USA:, 2009. 
[32] P. Bett, H. Thornton, The climatological relationships between wind and solar energy supply in Britain, Renewable Energy 87 (2016) 96110 .

[33] A. Scaife, A. Arribas, E. Blockley, A. Brookshaw, R. Clark, N. Dunstone, R. Eade, D. Fereday, C. Folland, M. Gordon, et al., Skillful long-range prediction of european and north american winters, Geophysical Research Letters 41 (2014) 2514-2519.

[34] I. Herceg-Bulić, F. Kucharski, North Atlantic SSTs as a link between the wintertime NAO and the following spring climate, Journal of climate 27 (2014) 186-201.

[35] T. N. Palmer, D. L. Anderson, The prospects for seasonal forecastinga review paper, Quarterly Journal of the Royal Meteorological Society 120 (1994) 755-793. 